Abstracta Iranica Iranica

Revue bibliographique pour le domaine irano-aryen

Volume 22 | 2001

Comptes rendus des publications de 1999

\title{
« Turkistan : Muslim Landscapes and Kazak Identity », JCAS, $2 / 1$ (1997), pp. 46-61.
}

\section{Stéphane A. Dudoignon}

\section{(2) OpenEdition}

1 Journals

\section{Édition électronique}

URL : http://journals.openedition.org/abstractairanica/36849

DOI : 10.4000/abstractairanica.36849

ISSN : 1961-960X

Éditeur :

CNRS (UMR 7528 Mondes iraniens et indiens), Éditions de l'IFRI

\section{Édition imprimée}

Date de publication : 15 mai 2001

ISSN : 0240-8910

Référence électronique

Stéphane A. Dudoignon, « «Turkistan : Muslim Landscapes and Kazak Identity », JCAS, 2/1 (1997), pp. 46-61. », Abstracta Iranica [En ligne], Volume 22 | 2001, document 382, mis en ligne le 17 février 2010, consulté le 13 octobre 2020. URL : http://journals.openedition.org/abstractairanica/36849 ; DOI : https://doi.org/10.4000/abstractairanica.36849

Ce document a été généré automatiquement le 13 octobre 2020.

Tous droits réservés 


\title{
« Turkistan : Muslim Landscapes and Kazak Identity ", JCAS, 2/1 (1997), pp. 46-61.
}

\author{
Stéphane A. Dudoignon
}

1 Dans la meilleure lignée des travaux de Devin DeWeese et de Robert D. McChesney, cette étude novatrice et séduisante est due à l'un des meilleurs connaisseurs actuels de l'islam au Qazaqstan, où il a résidé cinq années entières et dont il connaît parfaitement la langue. À partir d'une étude des pratiques et des discours religieux autour du mausolée d'Aḥmad Yasawî, dans la ville de Turkestan, l'A. remet en question l'idée reçue présentant les Qazaqs comme un peuple superficiellement islamisé, dans la culture duquel la religion n'occuperait qu'une place périphérique. L'analyse du niveau de connaissance locale de la tradition de Yasawî, d'une part, et de l'autre une réflexion sur la pertinence de divers signes d'islamité (musulmanšiliq) comme marqueurs culturels de l'identité qazaque incitent l'A. à conclure sur le rôle déterminant des paysages balisés par les sanctuaires de l'islam sur les notions les plus actuelles de communauté nationale au Qazaqstan.

\section{INDEX}

Thèmes : 8 . Soufisme 


\section{AUTEURS}

STÉPHANE A. DUDOIGNON

CNRS - Strasbourg 